\title{
The influence of orthodontic non-extraction treatment on the change in the inclination and position of incisors in the Europoid race
}

\author{
Koniarova $\mathrm{A}^{1}$, Sedlata Juraskova $\mathrm{E}^{2}$, Spidlen $\mathrm{M}^{2}$, Statelova $\mathrm{D}^{3}$ \\ OrthoSmile4U, Ltd., Martin, Slovakia. mojazubarka@post.sk
}

\begin{abstract}
AIM: To detect post-treatment change in the inclination and position of incisors in cases treated with orthodontic non- extraction therapy.

MATERIALS AND METHODS: The group consisted of 102 patients without extractions in lower and upper dental arch during orthodontic treatment. Cephalogram examination evaluated the position of the lower incisor to point A by Downs-pogonion line ( -1 to $\mathrm{APo}$ ) and inclination of the lower incisor to mandibular line ( -1 to $\mathrm{ML})$, position of the upper incisor to nasion-pogonion line ( +1 to NPo), inclination of the upper incisor to nasion-sella line (+1 to NS) and the size of the inter-incisival angle between upper and central lower incisor $(-1$ to +1$)$.

RESULTS: In $58 \%$ of cases, the difference in post-treatment and pre-treatment changes in the position of the (-1 to Apo) was within $\pm 2 \mathrm{~mm}$, which we considered stable. Statistically significantly higher values after treatment were in unstable rather than in stable cases with values (-1 to Apo), ( -1 to ML), (+1 to NPo). Statistically significantly lower value after the treatment was measured in unstable cases rather than in stable cases with a value $(-1$ to +1$)$. There was no statistically significantly different value in stable and unstable cases after treatment in values (+1 to NS).

CONCLUSION: The number of stable post-treatment cases was only $16 \%$ higher than the number of unstable cases. With the increasing value ( -1 to $A p o)$, the value $(-1$ to $M L)$ and ( +1 to NPo) increased, the value ( +1 to $-1)$ decreased. The value ( -1 to NS) not after treatment was not statistically significantly different in stable and unstable cases (Tab. 6, Fig. 4, Ref. 27). Text in PDF www.elis.sk.

KEY WORDS: orthodontic non-extraction treatment, stable, unstable.
\end{abstract}

\section{Introduction}

The aim of orthodontic treatment is to achieve a functional and aesthetically satisfactory result with a guarantee of long-term stability. To achieve such a result, it is first necessary to establish a detailed treatment plan. In orthodontics, we use the cephalogram, it is the crucial diagnostic component. It is essential for a correct treatment assessment and later for evaluation of the effect of the therapy (18). The decision as to the extraction or expansion therapy needs to be done at the beginning of the planning process.

The question of extraction versus expansion therapy has been a frequent topic of various discussions. At the beginning of the 20th century, E. H. Angle as a strong supporter of non-extraction therapy, advocated that every human person had to have 32 teeth, arranged in an ideal occlusion. His supporter, C. Case pointed out that the expansion will lead to non-aesthetic appearance and unstable result (11). As the time has passed, orthodontic treatment

${ }^{1}$ OrthoSmile4U, Ltd., Slovakia, ${ }^{2}$ Department of Orthodontics, Clinic of Dental Medicine, Medical Faculty of Palacký University in Olomouc, Czech Republic, ${ }^{3}$ Department of Stomatology and Maxillofacial Surgery, Jessenius Faculty of Medicine in Martin, Comenius University in Bratislava, Slovakia

Address for correspondence: A. Koniarova, MD, OrthoSmile4U, Ltd., Korunovo 15, SK-036 01 Martin, Slovakia.

Phone: +421.903665336 went through the periods of non-extractive and extractive trends. At the end of the 40s of the 20th century, thanks to Begg and Tweed, the era of extractions started, which is due to undesirable effects related to the extraction, such as: the bite deepening, an excess of space and the others, repeatedly criticized and debated. The period of $70 \mathrm{~s}$ and $80 \mathrm{~s}$ are non-extraction period, which, in fact, continues up to now (13).

Treatment planning usually begins in the lower dental arch due to the limited possibilities of obtaining space for inclusion of teeth into the arc $(1,2,3)$. Due to the stability of orthodontic result, it is not possible neither to expand lower dental arch transversally nor to distalize the molars $(14,15,16)$. Protrusion of lower incisors by more than $\pm 2 \mathrm{~mm}$ is unstable and risky due to gingival recessions, but, even so, in limited cases, we decide between this option and extraction process $(11,10)$.

Significant protrusion of lower incisors is caused by the application of Class II elastics for more than three months, levelling of the curve of Spee and application of removable functional appliances and the use of flexible, especially, nickel - titanium arch during the levelling phase of orthodontic treatment (17).

The necessity to do sagittal expansion in the lower dental arch has been associated with the efforts to achieve optimal facial aesthetics and occlusal result.

Retrusive position of lower incisors in the surgical cases in skeletal class III., as a result of bad habit and overbite in AII / 2 
Class in non-growing patients represent the existing exception for protrusion of lower incisors beyond the zone of stability.

The aim of this study, in cases treated during non-extraction orthodontic treatment, was to establish:

1) Post-treatment change in the position of lower incisor to point A by Downs-pogonion line ( -1 to APo).

2) To compare post-treatment change in the position of lower incisor to APo ( -1 to APo) and inclination of lower incisor to mandibular line ( -1 to ML) in stable and unstable cases.

3) To compare post-treatment change of the size of inter-incisival angle of upper and central lower incisors axis $(-1$ to +1$)$ in stable and unstable cases.

4) To compare post-treatment change in the position of upper incisor to nasion-pogonion line ( +1 to NPo) and inclination of upper incisor to nasion-sella line ( +1 to NS) in stable and unstable cases.

\section{Materials and methods}

SThe sudied group consisted of 102 patients, treated at the Department of Orthodontics, Clinic of Dentistry Medical Faculty, Palacký University, and University Hospital Olomouc treated by

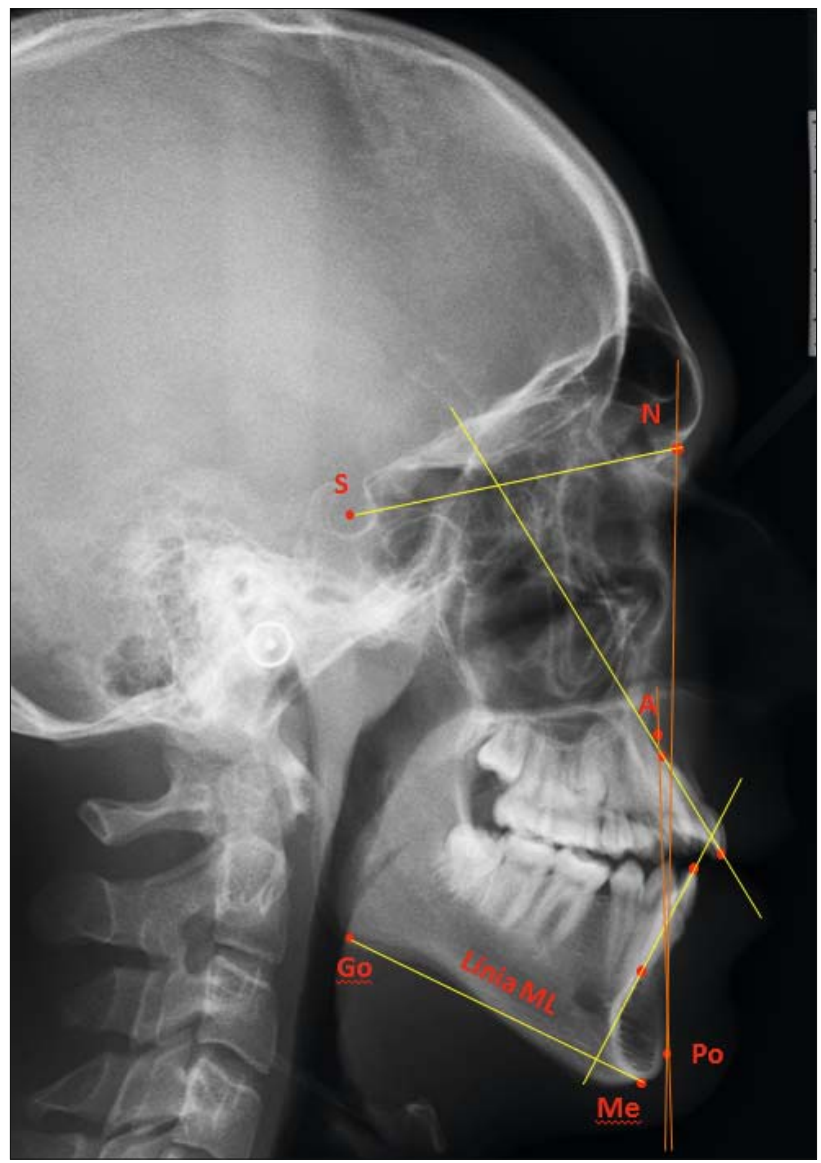

Fig. 1. The position and inclination of lower incisor to APo ( -1 to APo) and to ML ( -1 to ML). The inter-incisival angle to upper and central lower incisors axis $(-1$ to +1$)$. The position and inclination of upper incisor to NPo ( +1 to NPo) and to NS (+ 1 to NS).
PhD. students and experienced orthodontists. We collected material from 285 patients, in which fixed appliance was removed in 2015 (from 1.1. to 31.1.2015). Eligible were the patients with a complete dental arch in the range of 6-6, with non-extraction treatment of upper and lower dental arch, with a complete documentation (dental plaster models made before and after treatment, cephalograms and OPG made before and after treatment). Patients with severe skeletal malformation and after orthognathic surgery were not included. Of 102 patients, 65 were women and 37 men. The mean length of treatment was 27.5 months, with the mean age at the initiation of therapy 16 years and two months, the standard deviation was 6.39 . The youngest patient was 8 , when initiating the therapy, and the oldest was 39 years.

The relevant data in patients' records: patient age at the initiation of treatment, the patient's gender, duration of the active phase of the treatment. In cephalograms, we assessed: the position of lower incisor to APo, inclination of lower incisor to ML, interincisival angle of upper and central lower incisors axis, position of upper incisor to NPo and inclination of upper incisor to NS. While the $\mathrm{S}$ stands for the centre of sella turcica, $\mathrm{N}$ (nasion) - the most anterior point on frontonasal suture, $\mathrm{A}$ - the most posterior point on the front curve of the upper alveolus (by Downs), Po (pogonion) - the most anterior point on the mandibular symphysis, ML (mandibular line) - passes through the lowermost point of mandibular symphysis and is tangential to the posterior part of lower edge of the mandible (Fig. 1).

The position of lower incisor is defined as the distance from the cutting edge to APo. The mean distance is $3 \mathrm{~mm}$, the standard deviation is $\pm 2 \mathrm{~mm}$. If lower incisors are more inclined after the treatment as indicated by standard deviation, treatment result is considered unstable and according to it, we decide for the extraction or expansion therapy (12).

The inclination of lower incisor makes its longitudinal axis with ML. This value is $94^{\circ}$ an average, the standard deviation is $\pm 7 \mathrm{~mm}$. Post-treatment change in the inclination of the lower incisor to ML by more than indicated by the standard deviation is unstable (12).

Inter-incisival angle expresses a mutual inclination of upper and lower incisors. The mean value is $127^{\circ}$. The standard deviation is $\pm 8.5^{\circ}$. Too small value of this angle is called bimaxillary protrusion. When inter-incisival angle is too big, deep bite relapses (4).

Inclination of the upper incisor is measured with the angle formed between the longitudinal axis with NS line. The mean value is $104^{\circ}$. The standard deviation is $\pm 6.5^{\circ}$. This angle is bigger at protrusion and smaller at retrusion of upper incisors (4).

The position of the upper incisor is determined by the distance of its cutting edge to the NPo line. The mean value is $7 \mathrm{~mm}$. The standard deviation is $\pm 2.5 \mathrm{~mm}$. In large values of this distance, the upper incisors are protruding. In small values, they are in retrusion (4).

Cephalometric analysis was performed in Kefalo 4.07 program.

\section{Results}

1) The first aim of our research was to determine the post-treatment reposition of lower incisor to APo line ( -1 to Apo) in the patients with non-extraction therapy. 
Tab. 1. The post-treatment reposition of lower incisor to APo line (-1 to APo).

\begin{tabular}{lccc}
\hline & $\begin{array}{c}-1 \text { to APo prior } \\
\text { to treatment }\end{array}$ & $\begin{array}{c}\text {-to APo after } \\
\text { treatment }\end{array}$ & $\begin{array}{c}\text { difference }-1 \text { to } \\
\text { APo prior to and } \\
\text { after treatment }\end{array}$ \\
\hline $\mathrm{n}$ & 102 & 102 & 102 \\
mean & 2.62 & 4.49 & 1.87 \\
median & 3 & 4 & 2 \\
standard deviation & 2.78 & 2.5 & 2.38 \\
minimum & -3 & -1 & -4 \\
maximum & 8 & 11 & 8 \\
dissipation & 7.78 & 6.24 & 5.68 \\
\hline
\end{tabular}

The mean difference was $1.87 \mathrm{~mm}$ with the standard deviation of $2.38 \mathrm{~mm}$. The minimum value of this difference was $-4 \mathrm{~mm}$ and maximum difference was $8 \mathrm{~mm}$ (Tab. 1).

In 43 patients out of 102 , i.e. $42 \%$, the difference in the posttreatment and pre- treatment changes the position of lower incisors to APo line ( -1 to Apo) was more than $\pm 2 \mathrm{~mm}$, which we considered unstable. In 59 cases out of 102 , i.e. $58 \%$ the difference of values in the position of lower incisors to APo were up to $\pm 2 \mathrm{~mm}$, where the result of treatment is considered stable.

Tab. 2. The post-treatment change in the position of lower incisor to APo line ( -1 to APo) in stable and unstable cases.

\begin{tabular}{|c|c|c|c|c|c|c|}
\hline & $\begin{array}{c}-1 \text { to APo prior } \\
\text { to unstable }\end{array}$ & $\begin{array}{c}-1 \text { to APo after } \\
\text { unstable }\end{array}$ & $\begin{array}{c}\text { difference }-1 \text { to APo } \\
\text { prior to and after } \\
\text { treatment unstable cases }\end{array}$ & $\begin{array}{c}-1 \text { to APo prior } \\
\text { to stab. }\end{array}$ & $\begin{array}{c}-1 \text { to APo after } \\
\text { stab. }\end{array}$ & $\begin{array}{l}\text { difference }-1 \text { to APo } \\
\text { prior to and after } \\
\text { treatment-stable cases }\end{array}$ \\
\hline $\mathrm{n}$ & 43 & 43 & 43 & 59 & 59 & 59 \\
\hline mean & 1.85 & 5.41 & 3.72 & 3.19 & 3.81 & 0.58 \\
\hline median & 1 & 5 & 4 & 3 & 4 & 1 \\
\hline standard deviation & 2.97 & 2.58 & 2.33 & 2.5 & 2.21 & 1.32 \\
\hline minimum & -3 & 0 & -4 & -3 & -1 & -2 \\
\hline dissipation & 8.8 & 6.65 & 5.41 & 6.24 & 4.89 & 1.74 \\
\hline
\end{tabular}

Tab. 3. The post-treatment change in the inclination of lower incisor to ML ( -1 to ML) in stable and unstable cases.

\begin{tabular}{|c|c|c|c|c|c|c|}
\hline & $\begin{array}{l}\text {-1-ML prior } \\
\text { to unstab. }\end{array}$ & $\begin{array}{c}-1 \text { to ML after } \\
\text { unstab. }\end{array}$ & $\begin{array}{c}\text { difference }-1 \text { to } \mathrm{ML} \\
\text { prior to and after } \\
\text { treatment unstable cases }\end{array}$ & $\begin{array}{l}-1 \text { to } \mathrm{ML} \text { prior } \\
\text { to stab. }\end{array}$ & $\begin{array}{l}-1 \text { to ML after } \\
\text { stab. }\end{array}$ & $\begin{array}{c}\text { difference }-1 \text { to } M L \\
\text { prior to and after } \\
\text { treatment }- \text { stable cases }\end{array}$ \\
\hline $\mathrm{n}$ & 43 & 43 & 43 & 59 & 59 & 59 \\
\hline mean & 94.42 & 104.37 & 9.88 & 96.37 & 98.08 & 1.81 \\
\hline median & 93 & 105 & 9 & 96 & 97 & 2 \\
\hline standard deviation & 7.4 & 8.58 & 8.44 & 9.26 & 9.26 & 6.41 \\
\hline minimum & 78 & 85 & -12 & 78 & 80 & -13 \\
\hline dissipation & 54.76 & 73.63 & 71.17 & 85.79 & 85.74 & 41.07 \\
\hline
\end{tabular}

Tab. 4. The post-treatment change in the value inter-incisival angle $(-1$ to +1$)$ in stable and unstable cases.

\begin{tabular}{|c|c|c|c|c|}
\hline & +1 to -1 prior to unstab. & +1 to -1 after unstab. & +1 to -1 prior to stab. & +1 to -1 after stab. \\
\hline $\mathrm{n}$ & 43 & 43 & 59 & 59 \\
\hline mean & 133.21 & 115.56 & 127.68 & 125.27 \\
\hline median & 132 & 105 & 127 & 125 \\
\hline standard deviation & 15.49 & 8.8 & 11.83 & 9.66 \\
\hline minimum & 106 & 100 & 105 & 103 \\
\hline maximum & 171 & 140 & 155 & 142 \\
\hline dissipation & 239.92 & 77.36 & 139.98 & 93.32 \\
\hline
\end{tabular}

Tab. 5. The change in the position of upper incisor to NPo ( +1 to NPo) in stable and unstable cases.

\begin{tabular}{|c|c|c|c|c|}
\hline & +1 to NPo prior to unstab. & +1 to NPo after unstab. & +1 to NPo prior to stab. & +1 to NPo after stab. \\
\hline $\bar{n}$ & 43 & 43 & 59 & 59 \\
\hline mean & 5.77 & 7.07 & 5.97 & 5.78 \\
\hline median & 6 & 7 & 5 & 6 \\
\hline standard deviation & 3.67 & 2.7 & 3.79 & 3.17 \\
\hline minimum & 0 & 1 & 0 & 0 \\
\hline maximum & 15 & 13 & 15 & 12 \\
\hline dissipation & 13.48 & 7.27 & 14.34 & 10.07 \\
\hline
\end{tabular}


Tab. 6. The change in inclination of upper incisor to NS ( +1 to NS) in stable and unstable cases.

\begin{tabular}{|c|c|c|c|c|}
\hline & +1 to NS prior to unstab. & +1 to NS after unstab. & +1 to NS prior to stab. & $+1 \mathrm{kNS}$ after stab. \\
\hline $\mathrm{n}$ & 43 & 43 & 59 & 59 \\
\hline mean & 101.33 & 108.65 & 105.44 & 105.73 \\
\hline median & 104 & 109 & 105 & 105 \\
\hline standard deviation & 12.47 & 8.22 & 7.69 & 7.22 \\
\hline minimum & 69 & 92 & 91 & 87 \\
\hline maximum & 126 & 126 & 122 & 123 \\
\hline dissipation & 155.57 & 67.53 & 59.16 & 52.06 \\
\hline
\end{tabular}

2) The aim was to compare the post-treatment change in the position ( -1 to APo) and inclination ( -1 toML) of the lower incisor in stable and unstable cases.

The mean difference of value ( -1 to Apo) at the beginning and the end of treatment in stable and unstable cases was $3.14 \mathrm{~mm}$. The mean difference of -1 to ML value at the beginning and end of treatment in stable and unstable cases was $8.07^{\circ}$ (Tabs 2 and 3).

3) The other aim was to compare the post-treatment change in the position of inter-incisival angle in stable and unstable cases. The mean difference of value of inter-incisival angle $(-1$ to +1$)$ in stable and unstable cases at the end of treatment was $9.71^{\circ}$ (Tab. 4).

4) The aim was to compare the change in the position and inclination of upper incisor to the NPo (+1 to NPo) and to NS (+1 to NS) in stable and unstable cases.

The mean difference of value in the position of upper incisor to NPo in stable and unstable cases at the end of treatment was $1.29 \mathrm{~mm}$, the difference of value in the inclination of upper incisor to NS at the end of treatment in stable and unstable cases was $2.92^{\circ}$ (Tabs 5 and 6).

Due to the fact, that the data measured before and after treatment have a Gaussian distribution, to compare the measured values, a paired t-tests were used.

\section{Unstable cases}

$+\mathbf{1}$ to NS. $\mathrm{p}<0.0001$. Then, $1 \mathrm{k}$ NS was statistically significantly different before than after treatment. A $95 \%$ confidence interval $(-10.54,-4.11)$. Then +1 toNS was statistically significantly lower before than after.

$+\mathbf{1}$ to NPo. $\mathrm{p}=0.005$. Then, 1 to NPo was statistically significantly different before, after. A $95 \%$ confidence interval $(-2.20$, $-0.40)$. Then +1 to NPo was statistically significantly lower before than after.

$\mathbf{- 1}$ to $+1 . \mathrm{p}<0.0001$. Then $-1 \mathrm{k}+1$ was statistically significantly different before and after. A $95 \%$ confidence interval $(12.94,22.78)$. Then -1 to +1 was statistically significantly higher before than after.

$\mathbf{- 1}$ to ML. $\mathrm{p}<0.0001$. Then -1 to ML was statistically significantly different before and after. A $95 \%$ confidence interval $(-12.65,-7.26)$. Then, -1 to ML was statistically significantly lower before than after.

$\mathbf{- 1}$ to APo. $\mathrm{p}<0.0001$. Then -1 to APo was statistically significantly different before and after. A $95 \%$ confidence interval $(-4.37,-2.79)$. Then, -1 to APo was statistically significantly lower before than after.
Stable cases

+1 to NS. $p=0.792$. Then, +1 to NS was not statistically significantly different before, than after. A $95 \%$ confidence interval $(-2.47,1.89)$.

+1 to NPo. $p=0.525$. Then, +1 to NPo was not statistically significantly different before, after. A $95 \%$ confidence interval $(-0.40,0.77)$.

$\mathbf{- 1}$ to $+1 . p=0.112$. Then, -1 to +1 was not statistically significantly different before and after. A $95 \%$ confidence interval $(-0.58,5.39)$.

$\mathbf{- 1}$ to ML. $\mathrm{p}=0.047$. Then, 1 to ML was statistically significantly different before and after. A $95 \%$ confidence interval $(-3.40,-0.02)$.

$\mathbf{- 1}$ to APo. $\mathrm{p}=0.0008$. Then, -1 to APo was statistically significantly different before and after. A $95 \%$ confidence interval $(-0.97,-0.27)$. Then -1 to APo was statistically significantly lower before than after.

\section{Comparison of unstable and stable cases before treatment}

+1 to NS. $p=0.063$. Then, +1 to NS, before treatment, was not statistically significantly different in unstable than in stable. A $95 \%$ confidence interval $(-8.46,0.23)$.

+1 to NPo. $p=0.793$. Then, +1 to NPo before treatment was not statistically significantly different in unstable than in stable. A $95 \%$ confidence interval $(-1.70,1.30)$.

-1 to $+1 . p=0.048$. Then, -1 to +1 before treatment was statistically significantly different in unstable than in stable. A $95 \%$ confidence interval $(0.06,11.42)$. Then -1 to +1 before treatment was statistically significantly higher in unstable than in stable.

-1 to ML. $p=0.244$. Then, -1 to ML before treatment was not statistically significantly different in unstable than in stable. A $95 \%$ confidence interval $(-5.26,1.36)$.

-1 to APo. $p=0.020$. Then, -1 to APo before treatment was statistically significantly different in unstable than in stable. A $95 \%$ confidence interval $(-2.46,-0.22)$. Then, -1 to APo before treatment was statistically significantly lower in unstable than in stable.

\section{Comparison of unstable and stable cases after treatment}

+1 to NS. $p=0.068$. Then, +1 to NS, after treatment, was not statistically significantly different in unstable than in stable. A $95 \%$ confidence interval $(-0.23,6.07)$.

+1 to NPo. $p=0.031$. Then, +1 to NPo after treatment was statistically significantly different in unstable than in stable. A $95 \%$ confidence interval $(0.12,2.46)$. Then, +1 to NPo after treatment was statistically significantly higher in unstable than in stable. 
662-668

$\mathbf{- 1}$ to $+1 . \mathrm{p}<0.0001$. Then, -1 to +1 after treatment was statistically significantly different in unstable than in stable. A $95 \%$ confidence interval $(-13.40,-6.03)$. Then -1 to +1 after treatment was statistically significantly lower in unstable than in stable.

-1 to ML. $p=0.0007$. Then, -1 to ML after treatment was statistically significantly different in unstable than in stable. A $95 \%$ confidence interval $(2.72,9.86)$. Then, -1 to $\mathrm{ML}$ after treatment was statistically significantly higher in unstable than in stable.

$\mathbf{- 1}$ to APo. $\mathrm{p}=0.0014$. Then, -1 to APo after treatment was statistically significantly different in unstable than in stable. A $95 \%$ confidence interval $(0.65,2.60)$. Then, -1 to APo after treatment was statistically significantly higher in unstable than in stable.

\section{Discussion}

The first aim of our research was to establish post-treatment change in the position of the lower incisor to the APo line ( -1 to $\mathrm{APo}$ ) in 102 patients with non-extraction treatment. The most stable position of the lower incisor is considered the position before an orthodontic treatment (5). Out of 102 patients, 18 patients had a value of lower incisor position to A-Po line ( -1 to APo) prior to the treatment more than $5 \mathrm{~mm}$. This value is the result of dentoalveolar compensatory mechanism and is considered stable even though the values of absolute numbers indicated an extraction.

The mean distance of the position of the lower incisor to Apo ( -1 to $\mathrm{APo}$ ) is $3 \mathrm{~mm}$ with the standard deviation of $\pm 2 \mathrm{~mm}$. If lower incisors are more inclined after the treatment than indicated by the standard deviation, treatment outcome is unstable. The inclination of the lower incisor to the ML ( -1 to ML) is defined as the angle, which is formed by its longitudinal axis to the ML. The mean value of this angle is $94^{\circ} \pm 7^{\circ}$. If the result is over the value of the standard deviation, the position of the lower incisors is unstable.

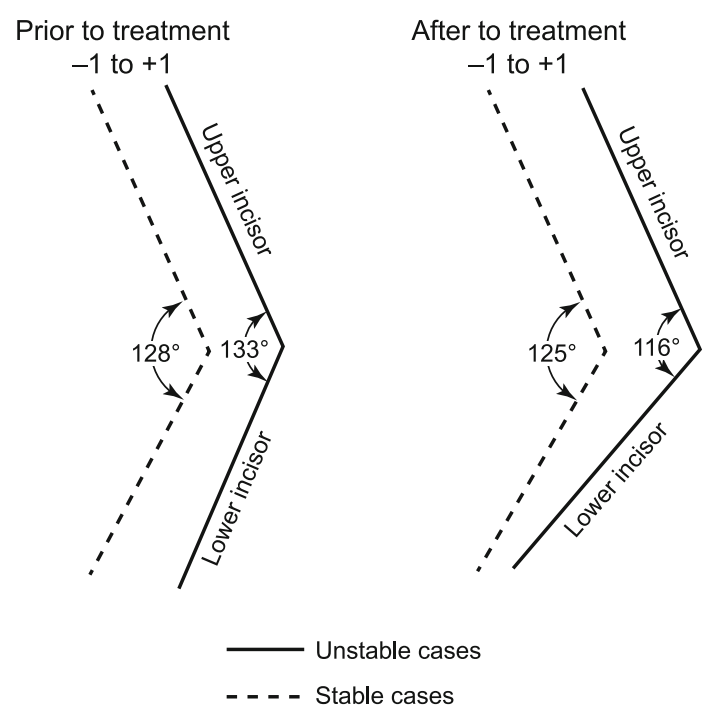

Fig. 2. Reduction of inter-incisival angle $(-1$ to +1$)$ of upper and central lower incisors axis in stable and unstable cases before and after treatment.
It results from our research that the mean difference of the values in the position of the lower incisor to APo ( -1 to APo) before and after treatment in 102 patients with non-extraction treatment was $1.87 \mathrm{~mm}$ with the standard deviation of $2.38 \mathrm{~mm}$. The minimum value of the difference was $-4 \mathrm{~mm}$ and maximum was $8 \mathrm{~mm}$. In 43 patients out of 102 , i.e. $42 \%$ the difference of pre-treatment and post-treatment value in the position of the lower incisor to APo ( -1 to APo) was more than $\pm 2 \mathrm{~mm}$, which we considered unstable. In 59 cases, i.e. $58 \%$, the result was stable.

The second objective was to compare the post-treatment change in the position ( -1 to APo) and the inclination of the lower incisor $(-1$ to $\mathrm{ML})$ in stable and unstable cases. The mean posttreatment change in the position of the lower incisor to APo ( -1 to APo) in stable cases was $3.81 \mathrm{~mm}$ and $5.41 \mathrm{~mm}$ in unstable cases. The mean post-treatment change in the inclination of the lower incisor to ML ( -1 to ML) in stable cases was 98.08 and $104.37^{\circ}$ in unstable cases. The mean difference of value ( -1 to APo) at the beginning and the end of the treatment in stable and unstable cases was $3.14 \mathrm{~mm}$, and difference of ( -1 to ML) at the beginning and the end of treatment in stable and unstable cases was $8.07^{\circ}$.

The question is, to what extent the inclination of the lower incisor over $\pm 2 \mathrm{~mm}$ and the change of lower incisor inclination over \pm 7 from the original position will be stable and how long the retention phase of treatment will last.

In some cases, long-term or lifelong retention is necessary, or the retention until completion of growth, or short retention, possibly as long as possible $(6,7,8)$. In order to ensure maximum stability, it is recommended to use fixed retainer in frontal segment of teeth in the combination with a removable retainer (9).

The third objective was to compare the post-treatment change in the position of inter-incisival angle in stable and unstable cases.

The inter-incisival angle expresses a mutual inclination of the upper central lower incisors ( -1 to 1$)$, with the mean value of $127^{\circ}$ $\pm 8.5^{\circ}$. Too small angle is called bimaxillary protrusion, which is aesthetically unsatisfactory in the Europoid race. When this angle is too big, deep bite relapses.

In our research, we found out that in stable cases, there was a reduction of this angle by 2.41 after the treatment and in unstable cases by $17.65^{\circ}$. The mean difference of value of the inter-incisival angle in stable and unstable cases at the end of treatment was $9.71^{\circ}$ (Fig. 2).

The last and the fourth objective was to compare changes in the position of the upper incisor ( +1 to NPo) and the inclination of the upper incisor to NS ( +1 to NS) in stable and unstable cases at the end of the treatment.

In unstable cases, the mean difference of the values in the position of the upper incisor to NPo (+1 to NPo) was $1.3 \mathrm{~mm}$ and in stable cases it was $-0.19 \mathrm{~mm}$. The mean difference of value in the position of the upper incisor to NPo $(+1$ to NPo) in stable and unstable cases at the end of treatment was $1.29 \mathrm{~mm}$.

The change of the upper incisor inclination to NS ( +1 to NS) in unstable cases has changed from $101.33^{\circ}$ to 108.65 on the average and in stable cases from $105.44^{\circ}$ to $105.73^{\circ}$. In stable cases, the mean difference after the treatment in the value of the upper incisor inclination was lower by $2.92^{\circ}$ than in unstable cases. 


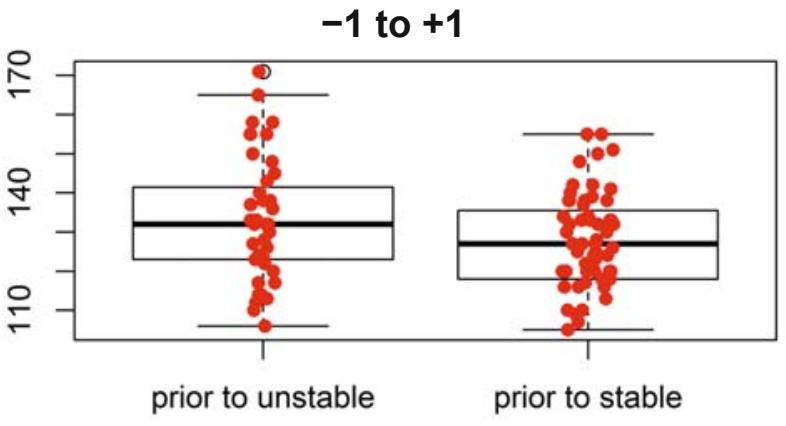

Fig. 3. Comparison of value inter-incisival angle to upper and central lower incisors axis $(-1$ to +1$)$ in stable and unstable cases before treatment.

Pandis et al (19) found a significant dependence between a labial inclination of lower incisors to ML line when levelling the curve of Spee, while Woods (20) and Braun (21) came to the conclusion that the inclination of lower incisors could be prevented if correct bite-raising mechanic are used.

Cambrink et al (22) studied, on a set of patients with Angle Class II, the impact of Class II. elastics on dentoskeletal changes. He found out that Class II elastics did not have significant effect on it, but they caused a labial inclination of incisors to APo and ML line. Similar results have also been published by Reddy et al (23).

Saelens (24) compared therapeutic changes to lateral cephalograms in extraction and non-extraction cases treated with Begg technique. She found out that during treatment the lower incisor position relative to PMV (pterygomaxillary vertical plane) did not change significantly and the upper incisors moved backwards approximately $2 \mathrm{~mm}$ in both extraction group. This was not reflected in a significant change in lip position. In the non-extraction group, tooth alignment was accompanied by a significant proclination of incisors and a comparable forward movement in the lip region, when measured relative to PMV.

Verma (25) compared the results of orthodontic treatment in extraction and non-extraction group. She found out that after treatment, it was observed that the soft tissue convexities were straightened in the extraction groups more than in the non-extraction groups, the upper and lower lips were more returnable in the extraction groups than in the non-extraction groups.

Kocaderili (26) compared the changes on soft tissues of the face after orthodontic treatment in the extraction and the nonextraction group. In the non-extraction group, a forward tipping of the incisors was noted. The changes in the incisor inclination proved to be significant.

Germeca's (27) research confirmed that in the non-extraction group, the maintenance of maxillary incisor position, a slight protrusion of the mandibular incisors and the upper and lower lip were observed at the end of treatment.

\section{Conclusion}

1) After treatment changes in position -1 to APo In $58 \%$ of the patients, the difference between pre-treatment

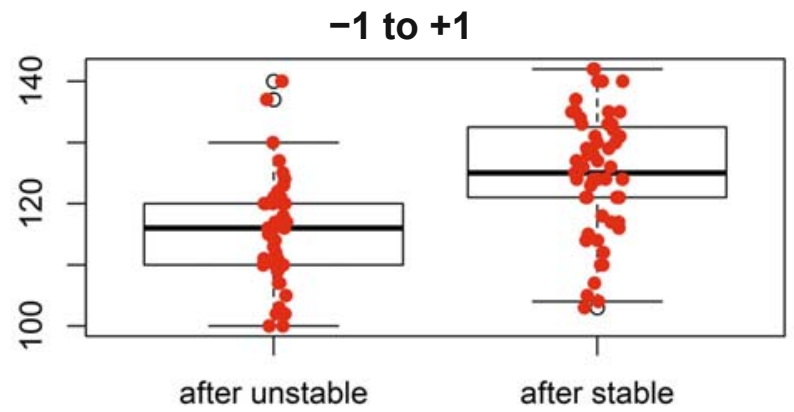

Fig. 4. Comparison of value inter-incisival angle to upper and central lower incisors axis $(-1$ to +1$)$ in stable and unstable cases after treatment.

and after treatment value -1 TO APo was up to $\pm 2 \mathrm{~mm}$. The result of the treatment in these cases could be considered stable.

2) After the treatment changes in the position and inclination -1 to $\mathrm{APo},-1$ to $\mathrm{ML},+1$ to NS, +1 to NPo in stable and unstable cases.

There were statistically significantly higher values -1 to APo, -1 to $\mathrm{ML},+1$ to NPo after treatment in unstable cases than in stable cases.

After treatment value +1 to NS was not statistically significantly different in comparison with stable and unstable cases.

3) After treatment changes -1 to +1

There was a significantly lower value -1 to +1 unstable cases than in stable cases (Figs 3 and 4).

\section{References}

1. Kamínek, M, Štefkova M.: Indication und Kontraindication der Behandlung des Engstandes mittels festsitzender Apparaturen und Extractionstherapie. Stomatologie DDR 1985; 35 (11): 648-654.

2. Kamínek M. Lokální okluzální a skeletální faktory při indikaci extrakcí. I. část. Čs Stomat 1987; 87 (2): 105-112.

3. Kamínek M. Lokální okluzální a skeletální faktory při indikaci extrakcí. II. část. Čs Stomat 1987; 87 (3): 226-231.

4. Kamínek M. et al. Ortodoncie. Semily: Galén, 2014, 55-56.

5. Blake M, Biby K. Retention and stability: a review of the literature. Amer J Orthodont Dentofac Orthop 1998; 114: 299-306.

6. Artun J, Spadafora AT, Shapiro PA. A 3-years follow-up study of various types of orthodontic canine-to-canine retainers. Eur J Orthodont 1997; 19: 501-509.

7. Little RM, Riedel RA, Artun, J. An evaluation of changes in mandibular anterior alignment from 10 to 20 years postretention. Amer J Orthodon. 1988; 93: 423-428.

8. Zachrisson BU. Clicical experience with direct-bonded orthodontic retainers. Amer J Orthodont 1977; 71: 440-448.

9. Lang G, Alfter G, Goz G, Lang GH. Retention and stability - Taking various treatment parameters into account. J Orofac Orthoped 2002; 63 (1): $26-41$.

10. Kamínek M, Štefkova M. Ortodoncie II. Olomouc: Univerzita Palackého, 1991. 
662-668

11. Proffit WR, Fields HW, Sarver DM. Contemporary Orthodontics 4th ed. St. Louis: Mosby 2007.

12. Kamínek M, Štefkova M. Ortodoncie I. Olomouc, 2001.

13. Navrátilova Z. Labial inclination of lower incisors in non-extraction therapy with fixed appliance. Professional paper for attestation in Orthodontics. Olomouc, 2013.

14. Little RM, Wallen TR, Riedel RA. Stability and relapse of mandibular anterior alignment-first premolar extraction cases treated by traditional edgewise orthodontics. Amer J Orthodont 1981; 80, 349-365.

15. Uhde MD, Sadowsky C, BeGole EA. Long-term stability of dental relationship after orthodontic treatment. Angle Orthodont 1983; 53 (3): 240-252.

16. Sadowsky C, Schneider BJ, BeGole EA. A long term stability after orthodontic treatment: nonextraction with prolonged retention. Amer J Orthodont Dentofac Orthop 1994; 106: 243-249.

17. Hanuliakova Z. Evaluation of fixed appliance treatment in the lower dental arch in non-extraction therapy. Olomouc, 2016.

18. Thurzo A, Javorka V, Stanko P, Lysy J, Suchancova B, Lehotska V, Valkovic L. Digital and manual cephalometric analysis. Bratisl Lek Listy 2010; 111 (2): 97-100.

19. Pandis $\mathbf{N}$ et al. Effects of levelling of the curve of Spee on the proclination of mandibular incisors and expansion of dental arches: prospective clinical trial. Aust Orthodont J 2010; 26 (1): 61-65.
20. Woods M. A reassessment of space requirements for lower arch levelling. J Clin Orthodont 1986; 20 (11): 770-778.

21. Braun S, Hnat WP, Johnson BE. The curve of Spee revisited. Amer J Orthodont Dentofac Orthoped 1996; 110: 206-210.

22. Combrink FJ, Harris AM, Steyn CL, Hudson AP. Dentoskeletal and soft -tissue changes in growing class II malocclusion patients during nonextracion orthodontic treatment. J South Afr Dent Assoc 2006; 61 (8): 344-350.

23. Reddy P, Kharbanda OP, Duggal R, Parkash H. Skeletal and dental changes with nonextraction Begg mechanotherapy in patients with Class II Division 1malocclusion. Amer J Orthodont Dentofac Orthop 2000; 118 (6): 641-648.

24. Saelens NA, De Smit AA. Therapeutic changes in extraction versus nonextraction orthodontic treatment. Eur J Orthodont 1998; 20: 225-236.

25. Verma SL, Sharma VP, Tanton P, Singh GP, Sachan K. Comparison of esthetic outcome after extraction or nonextraction orthodontic treatment in class II division 1malocclusion patients. Contemp Clin Dent 2013; 4 (2): 206-2012.

26. Kocadereli I. Changes in soft tissue profile after orthodontic treatment with and without extractions. Amer J Orthodont Dentofac Orthoped 2002; 122: 67-72.

27. Germec D, Taner TU. Effects of extraction and nonextraction therapy with air-rotor stripping an facial esthetic in postadolescent borderline patients. Am J Dentofac Orthop 2008; 133: 539-549.

Received July 5, 2017. Accepted August 2, 2017. 